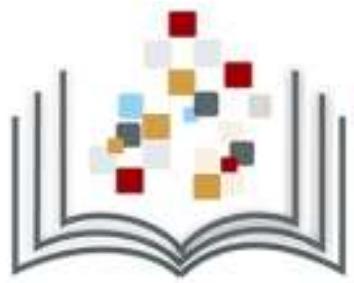

\title{
GESTÃO DE EVENTOS CIENTÍFICOS: UMA REALIDADE NA EESC/USP
}

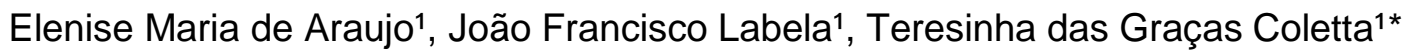 \\ ${ }^{1}$ Serviço de Biblioteca Prof. Dr. Sergio Rodrigues Fontes - Escola de Engenharia São \\ Carlos - Universidade de São Paulo - São Carlos (SP) - Brasil \\ *Autor correspondente: coletta@sc.usp.br
}

\begin{abstract}
Como citar:
ARAUJO, Elenise M.; LABELA, João F.; COLETTA, Teresinha das G.. Gestão de eventos científicos: uma realidade na EESC/USP. In: WORKSHOP DE EDITORAÇÃO CIENTÍFICA, 9., 2016, São Paulo. Anais... São Paulo: Associação Brasileira de Editores Científicos, 2016. p.1823

DOI: http://dx.doi.org/10.21452/wec.IXwec.2016.0004
\end{abstract}

\section{RESUMO}

A publicação da Comunicação Científica é a atividade fundamental para o desenvolvimento e manutenção da Sociedade da Informação e das atividades fins nas Universidades e Centros de Pesquisa. O Serviço de Biblioteca da Escola de Engenharia de São Carlos da Universidade de São Paulo (EESC-USP), atento às novas demandas informacionais, implementou o uso do Sistema Online de Acompanhamento de Conferências (SOAC) na versão traduzida realizada pelo lbict, do Open Conference System (OCS). Visando racionalizar os esforços das comissões organizadoras, 0 Serviço de Biblioteca oferece apoio e treinamento na plataforma e gerencia os eventos científicos no Portal de Eventos Científicos da EESC-USP, que hospeda atualmente cinco eventos. O processo de inserção no Portal e os detalhes de customização da interface são desenvolvidos em conjunto com as comissões organizadoras que podem, a partir da plataforma, usufruir de uma variedade de facilidades como: gerenciamento das inscrições, submissão de trabalhos, processo de avaliação, credenciamento de avaliadores e publicação e atribuição de International Standard Book Number (ISBN) aos anais eletrônicos. Considera-se relevante programar outras melhorias ao serviço de apoio à eventos científicos como a atribuição do Digital Object Identifier (DOI) aos trabalhos apresentados, e integração dos metadados à outras bases de dados institucionais.

\section{INTRODUÇÃO}

\section{A COMUNICAÇÃO CIENTÍFICA}

A Comunicação Científica no âmbito nacional e internacional se adequa frente ao grande número de soluções advindas das novas Tecnologias de Informação e Comunicação (TIC) e os gestores de eventos científicos se deparam com questões sobre as melhores formas de gerenciar o volume de informação e de conhecimento.

Valério e Pinheiro (2008) afirmam que a produção do conhecimento alavancou a ciência, visto o número crescente da literatura, técnicas e especializações de áreas. No entanto, na mesma proporção do crescimento exponencial da ciência, nota-se a necessidade de organizar o acesso e a oferta de informação. Segundo Valério e Pinheiro (2008, p. 160) "a ciência é surpreendida por novos fluxos de informação. A Internet, nova protagonista desse espetáculo, permitiu a milhares de novos usuários de informação trafegar na grande rede a cada instante, ampliando exponencialmente o 
público em potencial ao acesso da comunicação e da informação".

Os eventos científicos que ocorrem constantemente no ambiente acadêmico são comparados, no âmbito desse trabalho, a um grande sistema de gestão do conhecimento, pois cumprem etapas para criar, capturar, refinar, armazenar, gerenciar e disseminar o conhecimento produzidos nas universidades e centros de pesquisa por seus principais autores: pesquisadores, especialistas alunos e docentes.

Segundo Moresi (2001, p. 35) a organização do conhecimento formal em uma instituição é realmente, "um grande desafio a ser vencido" e os responsáveis por essa tarefa devem utilizar modernas tecnologias de informação para sistematizar, aprimorar e acelerar a gestão do conhecimento.

Nesse sentido, as instituições mantêm veículos formais de divulgação do conhecimento, visando a troca de experiências e a apresentação de resultados de pesquisa. Esses ambientes promovem a discussão técnica que pode ou não validar métodos e resultados de pesquisas garantindo o avanço da ciência em determinada área do conhecimento.

Secaf (2007) explica que os eventos científicos possuem características específicas e podem ser designados como: congresso, jornada, encontro, convenção, workshop, fórum, seminário, simpósio, painel, mesa redonda entre outros. Porém, todos eles tem pontos em comum que são os requisitos de: constituição de uma comissão organizadora e de um comitê técnico e científico, elaboração da programação dos temas e definição das sessões de apresentações orais e de pôsteres. Outras características como a abrangência do evento, duração, número de participantes e especialidades sobre os temas abordados, são utilizadas para designar cada tipo de evento. Segundo Secaf (2007, p. 81) "na atual fase de evolução tecnocientífica, é impossível imaginar que um profissional não inclua a participação em eventos em seu processo de educação continuada (intra ou extra institucional/empresarial)". Assim, evidenciam-se as necessidades dos pesquisadores em participarem e formularem eventos para efetivamente realizarem a divulgação da ciência e dos conhecimentos gerados nas universidades e centros de pesquisas.

Mueller e Caribé $(2010$, p. 28) ressaltam que as "[...] iniciativas de divulgação científica crescem em número e diversidade, tornando-se cada vez mais elaboradas" com o objetivo principal de levar à sociedade os conhecimentos produzidos por cientistas.

Os veículos de disseminação científica tiveram a sua visibilidade ampliada a partir do uso da internet. Antes limitados aos ambientes acadêmicos institucionalizados nas universidades e centros de pesquisas ficavam acessíveis apenas aos cientistas e pesquisadores especialistas que usavam as bibliotecas.

Atualmente, os gestores e organizadores de eventos científicos enfrentam desafios para realizar a curadoria dos dados gerados antes, durante e depois do evento. Assumem a complexa tarefa de gerenciar o evento como um todo que envolve desde a programação do evento, os diferentes aspectos das inscrições, a submissão de trabalhos, a designação de avaliadores, a comunicação com autores, avaliadores e membros do comitê científico e outras atividades que demandam tempo e dedicação da equipe organizadora. Além desses aspectos estruturais, os organizadores também se preocupam em produzir os anais do evento e manter um site de divulgação na web. Geralmente as equipes de cada evento desenvolvem uma página na web para agrupar as informações essenciais e o conteúdo apresentado em cada um deles.

Nesse contexto, o Serviço de Biblioteca Prof. Dr. Sérgio Rodrigues Fontes da Escola de Engenharia de São Carlos da Universidade de São Paulo (EESC-USP), procurada por algumas comissões de organização de eventos científicos locais para gerar os anais eletrônicos, buscou inovar no atendimento dessa demanda e passou a utilizar a plataforma Open Conference Systems (OCS) para apoiar a gestão dos eventos na Escola. 


\section{OPEN CONFERENCE SYSTEMS (OCS)}

O Public Knowledge Project (PKP) surgiu de uma iniciativa na University of British Columbia e atualmente conta com a parceria da Simon Fraser University e da Stanford University. O projeto nasceu com o objetivo de apoiar o trabalho das bibliotecas universitárias que oferecem suporte a comunicação científica e de gerenciamento de repositórios institucionais, revistas on-line, hospedagem de conferências e coleções digitais, curadoria dos dados de pesquisa, gestão dos sistemas de teses e dissertações eletrônicas. Com treze anos de existência o PKP deixou de ser apenas um projeto e assumiu a posição de canal open source da comunicação científica. O PKP sustenta as plataformas de publicação: Open Journal Systems (OJS) e Open Conference Systems (OCS), com Open Harvester Systems (OHS) utilizado na indexação do conteúdo nestes sistemas e em outros.

Com mais de 10.000 instalações ao redor do mundo, os softwares OJS, OCS, e OHS, apresentam-se como importantes soluções de código aberto desenvolvidas por uma equipe de pesquisadores e bibliotecários para apoiar a gestão da publicação acadêmica. Utilizados por editores de revistas acadêmicas e independentes, as soluções do PKP ajudam a ampliar a visibilidade da revista ou da conferência proporcionando a disseminação do conhecimento para toda comunidade científica em nível nacional e internacional.

Destaca-se nesse trabalho, a funcionalidade da plataforma OCS de editoração acadêmica que segundo Pinto (2011) é utilizada em mais de 1.600 sites para administrar e publicar conferências acadêmicas na web. Segundo Prado (2016) o OCS foi:

Projetado para reduzir o tempo e a energia devotados à rotina de administração de uma conferência [...] também aperfeiçoa o arquivamento e a eficiência do processo editorial e procura melhorar a qualidade acadêmica e editorial das publicações oriundas de conferências através de inovações que englobam processos editoriais e recursos de indexação aprimorados.

No Brasil, o Instituto Brasileiro de Informação em Ciência e Tecnologia (Ibict) traduziu o OCS que passou a ser nomeado Sistema On-line de Acompanhamento de Conferências (SOAC). A cartilha produzida por Shintaku, Brito e Fleury (2014) apresenta as instruções de uso da plataforma. O SOAC/OCS permite entre outras funcionalidades: a criação e o gerenciamento do evento e de suas diferentes edições, a chamada de trabalhos, aceite eletrônico dos trabalhos, comunicação com autores, avaliadores e diretores de área, avaliação por pares, publicação de anais e recursos de póspublicação. É um sistema completo para a gestão dos dados permitindo o upload de arquivos, a edição de metadados e da interface gráfica, assim como a inserção de imagens e de links remissivos para sites externos. O SOAC/OCS apresenta recursos de busca detalhada por termos, nome dos autores, título, resumo, texto completo, data, termos indexados por área do conhecimento, assunto e cobertura.

Ao verificar o uso da plataforma SOAC no Brasil constatou-se que algumas instituições a utilizam especificamente para a gestão de eventos de cunho científico. Dentre as instituições usuárias destacam-se: Universidade Federal de Minas Gerais (UFMG), Universidade Federal de Lavras (UFLA), Universidade de Brasília (UnB), Universidade Estadual de Londrina (UEL), Instituto Federal de Educação, Ciência e Tecnologia de Santa Catarina (IFSC), Universidade Federal de Uberlândia (UFU), Universidade Regional de Blumenau (FURB), Instituto Federal de Educação, Ciência e Tecnologia do Rio Grande do Sul (IFRS) e o Instituto de Artes da Universidade Estadual de Campinas (UNICAMP) que publica o índice de autores de um evento internacional sobre Teoria e Análise Musical. Mas ao analisar os sites, verificou-se que, em sua 
maioria, são ações isoladas e quando institucionais, são ações esporádicas. Apesar do número de instituições usuárias do SOAC no Brasil, não se encontrou publicações com relatos de experiências ou indicativos com ações para o compartilhamento de novas customizações e melhorias para a plataforma. A constituição de uma rede de apoio aos usuários do SOAC no Brasil traria muitos benefícios e com certeza agregaria muito valor ao gerenciamento e divulgação da comunicação científica nacional.

\section{METODOLOGIA}

O Serviço de Biblioteca da EESC-USP atento às novas demandas locais para gestão de eventos científicos iniciou em maio de 2016, as atividades de implantação do Portal de Eventos Científicos da EESC, com o objetivo de racionalizar os esforços das comissões organizadoras de eventos da graduação e pós-graduação.

A proposta do Portal foi apresentada inicialmente à diretoria da Escola, a partir da demanda da comissão organizadora da Semana de Engenharia Aeronáutica e, por sugestão foi levada a apreciação das comissões de Graduação e Pós-Graduação da EESC. Ambas consideraram pertinentes a ação no âmbito da Escola.

O software instalado no servidor da EESC foi analisado pela equipe da Biblioteca e alguns detalhes da interface gráfica foram customizados e continuam em desenvolvimento para atender os padrões institucionais.

A dinâmica de apoio que a Biblioteca oferece aos organizadores de eventos locais envolve várias etapas como: a apresentação do Portal e de suas funcionalidades e facilidades; a elaboração de formulários de avaliação; elaboração do template em suas diferentes modalidades (resumo, trabalho completo, pôster, resumo expandido e apresentação oral); padronização de template segundo as normas do Comitê 14 da Associação Brasileira de Normas Técnicas (ABNT); credenciamento de autores e avaliadores; treinamento para executar funções de diretores e gerentes gerais no SOAC visando dar autonomia aos organizadores para gerir o evento.

A Biblioteca realiza também a indexação dos metadados utilizando o protocolo para coleta do software que garante padronização. No processo de pós-publicação a Biblioteca atua no gerenciamento dos anais eletrônicos, validando e conferindo os dados gerados no sistema e providenciando o pedido de ISBN da publicação junto a Biblioteca Nacional (BN). Os trabalhos publicados no Portal são inseridos no banco de dados bibliográfico da USP, o Dedalus, para que manter o sincronismo entre as duas plataformas e a produção técnica-científica da Unidade seja atualizada constantemente.

Os trabalhos publicados no Portal de Eventos Científicos da EESC são de acesso aberto e as funcionalidades pertinentes ao software permitem a busca e navegação por autor e título, acesso ao texto completo e a coleta dos metadados por provedores de serviço, permitindo a indexação em outros serviços da web.

\section{RESULTADOS E DISCUSSÃO}

Até outubro de 2016, o Portal reuniu cinco eventos científicos de abrangência nacional em nível de graduação e pós-graduação, num total de 673 páginas de conteúdo em PDF e dispõe de ferramentas de leitura tais como: "Como citar este documento", "Versão de impressão", "Look up terms" e "Itens relacionados".

Os eventos hospedados no Portal são: I Simpósio do Programa de PósGraduação em Engenharia Mecânica da EESC-USP (SiPGEM); V Simpósio de Iniciação Científica da Engenharia Elétrica; Simpósio em Ciência e Engenharia de Materiais; XIII Semana da Engenharia Ambiental EESC-USP; XIII Semana de Engenharia Aeronáutica EESC-USP.

As customizações realizadas para cada evento atenderam em primeiro lugar a demanda da comissão organizadora. As alterações em comum envolveram a inserção 
de cabeçalhos, rodapé e logotipo da conferência; indicação do link para o site do evento; inclusão na barra de navegação de link para o guia de sustentabilidade em eventos acadêmicos, para orientar o uso racional de recursos nessas ocasiões. (LEME, MORTEAN e BRANDÃO, 2014).

Uma das conferências hospedadas utilizou nova folha de estilos e do tema na administração da área web. Essa iniciativa contribuiu para melhoria da interface e do domínio da plataforma pela equipe da Biblioteca. Para as futuras conferências outros temas serão localizados nas bibliotecas disponíveis na web e a ideia é personalizar ainda mais cada evento, fornecendo maior identidade visual.

\section{CONCLUSÕES}

A iniciativa do Serviço de Biblioteca da EESC, ao desenvolver o Portal de Eventos Científicos, gerou grande expectativa entre as comissões organizadoras e comitês científicos da Unidade. Constatou-se que existe um interesse na atribuição do DOI para os artigos publicados nos anais eletrônicos. Neste sentido, está em andamento junto ao Departamento Técnico do Sistema Integrado de Bibliotecas da USP (DT/SIBI-USP) as tratativas para essa implementação. Com isso, será possível colaborar na melhoria da disseminação da produção técnica-científica, utilizando o DOI nas referências e apoiando os usuários a citar documentos que possuam esse identificador.

Considera-se que depois dessa fase inicial, o Portal possa oferecer às comissões condições de hospedar e manter as edições retrospectivas dos eventos. Estima-se que no prazo de um ano o conteúdo do Portal seja no mínimo duplicado, visto que há condições de atender os nove Departamentos da Escola que promovem seus eventos periodicamente. Essa perspectiva está fundamentada na sustentabilidade e segurança que o Portal e a equipe da Biblioteca oferecem para realizar a migração de conteúdo dos eventos e solucionar problemas como as dificuldades de manutenção de páginas web e a vulnerabilidade dos dados quando mantidos em servidores externos.

A expectativa da Biblioteca é dar continuidade ao uso do software e da plataforma e aprimorar algumas funções como realizar a indexação dos metadados utilizando as categorias definidas no Vocabulário Controlado da USP e realizar a permuta de dados com outras bases de dados.

\section{AGRADECIMENTOS}

Os autores agradecem o apoio dos servidores: Ricardo Lamon Cerra (Técnico de rede de computador da Seção Técnica de Informática da EESC-USP) e Alexander Munaiar (Técnico de informática/webdesigner do Departamento de Engenharia Elétrica da EESC-USP).

\section{REFERÊNCIAS}

LEME, Patrícia.C.S.; MORTEAN, Alan.F.; BRANDÃO, Maicom.S. Sustentabilidade em eventos acadêmicos: guia prático para Instituições de Educação Superior. 2014. Disponível em:

$<$ http://www.sti.eesc.usp.br/biblioteca/images/soac/eesc_sga_sustentabilidade_em_ev entos_academicos.pdf>. Acesso em: 16 set. 2016.

MORESI, Eduardo Amadeu Dutra. Inteligência organizacional: um referencial integrado. Ci. Inf., [s.I.], v. 30, n. 2, p.35-46, ago. 2001. FapUNIFESP (SciELO). http://dx.doi.org/10.1590/s0100-19652001000200006 
MUELLER, Suzana P.m.; CARIBÉ, Rita de C. do V. A comunicação científica para o público leigo: breve histórico. Informação \& Informação, [s.I.], v. 15, n. 1, p.13-30, 15 dez. 2010. Universidade Estadual de Londrina. http://dx.doi.org/10.5433/19818920.2010v15n1espp13.

PINTO, B. Mario. Public Knowledge Project 2.0: the Value Proposition. 2011. Disponível em: <https://pkp.sfu.ca/files/PKP-Sustainability-Prospectus.pdf>. Acesso em: 20 set. 2016.

SECAF, Victoria. Artigo científico: do desafio à conquista: enfoque em teses e outros trabalhos acadêmicos. 4. ed. São Paulo: Martinari, 2007. 138 p.

SHINTAKU, Milton; BRITO, Ronnie F.; FLEURY, Andrea. SOAC/OCS para gerentes gerais. 2014. Disponível em: <http://labcoat.ibict.br/portal/wpcontent/uploads/2015/03/ltem-12-Digital-2.pdf>. Acesso em: 20 set. 2016.

VALEIRO, Palmira M.; PINHEIRO, Lena V. R. Da comunicação científica à divulgação. Transinformação, [s.I.], v. 20, n. 2, p.159-169, ago. 2008. FapUNIFESP (SciELO). http://dx.doi.org/10.1590/s0103-37862008000200004.

PALAVRAS-CHAVE: Eventos científicos. SOAC/OCS. Publicação científica. 